\title{
LOS RESTOS DE UN PENSAMIENTO HUMANISTA O EL DASEIN COMO COLECCIONISTA EN SER Y TIEMPO.
}

\author{
JUAN PABLO GARAVITO ZULUAGA \\ Pontificia Universidad Javeriana \\ Bogotá
}

\begin{abstract}
RESUMEN: La confrontación de Heidegger con el humanismo es bien conocida: es la forma de toda metafísica entendida desde la subjetividad. La tesis que se defiende en el ensayo es que hay otra forma de entender su relación con el humanismo desde un punto de vista espacial. Se establece una relación entre la concepción del espacio cotidiano y de lo «a la mano» en Ser y Tiempo, y la noción de colección en los primeros humanistas. De este modo se muestra que el humanismo temprano no es un antecesor del subjetivismo cartesiano, y que, tal como lo proponen Gadamer o Grassi, representa una corriente que bebe de fuentes diferentes a la dominante en el pensamiento occidental. Heidegger, de un modo indirecto, apropia ese pensamiento para su proyecto de Ser y Tiempo.
\end{abstract}

PALABRAS CLAVE: colección; cotidianidad; espacio; utopía; vita activa.

\section{Remains of humanist thinking or Dasein as collector in Being and time}

ABSTRACT: The confrontation between Heidegger and the humanistic tradition is well known: it is the form of all metaphysics as subjectivity. We propose in this essay that there is another way to understand his relationship with this humanist tradition from a spatial standpoint. We postulate a connection between the conception of everyday space and of «readiness-to-hand" (Zuhandenheit) in Being and Time, and the conception of collection in the early humanists. From here it is possible to show that early humanism was not just a forerunner of Cartesian subjectivity, and that it represents, as postulated by Gadamer or Grassi, an underground current that emanates from a different metaphysical source, than the one that has dominated western thought. Heidegger appropriates, in an indirect mode, this thought for his project in Being and Time.

KEY WORDS: collections; everydayness; space; utopia; vita activa.

El presente escrito se pregunta, ¿podemos ver en la estructura de lo a la mano (Zuhandenheit) y de la circunspección ocupada (umsichtiges Besorgen) de la analítica de la cotidianidad en Ser y Tiempo los restos de un ideal del humanista como coleccionador, que desde Petrarca hasta el Barroco caracteriza al intelectual, al filósofo y al científico y que luego va a transformarse en un ideal utópico? Si esto es así, entonces podemos reevaluar la relación de Heidegger con el humanismo desde un punto de vista espacial y determinar de un modo más profundo su presencia en el proyecto de Ser y tiempo. Así tendríamos que constatar la influencia en dicho proyecto de un humanismo que no será visto ya como antecesor del yo cartesiano como fuente de toda verdad, sino en el que el humanista entra en resonancia con el mundo y con lo por él amado y deseado, en la cercanía de aquello que protege y acerca en su colección. Nuestro objetivo no es "probar» nuestro argumento en cuanto tratamos de forzar la entrada en él de todas las afirmaciones heideggerianas sobre la cotidianeidad del Dasein, sino la de mostrar semejanzas estructurales entre el mundo circundante y cotidiano (Umwelt) del Dasein y el arte de la colección tal como emerge entre los humanistas del siglo XIV, por un lado, y entre la utopía clásica de los siglos XVI y XVII y la aspiración del Dasein a superar su caída en el mundo de lo público y del Uno. 
El Dasein habita su mundo circundante (Umwelt) rodeado del ente a la mano y ello quiere decir, lo habita en tanto su agarrar aquello que le sale al encuentro, moldea y adapta lo ente a su propia manera de agarrarlo, en tanto su escondida extrañeza queda reducida a la familiaridad de sus dedos cerrados en torno a una forma disuelta bajo su propio cuerpo. De su empleo técnico el ente no sabe nada, pues el para qué de su finalidad propia queda absorbido en la proyección de quien utiliza lo ente como herramienta en la que su aparecer mismo se desvanece. En el juego del aparecer/desaparecer del ente en su ser utilizado, en su ser agarrado, en su pertenencia al mundo circundante, cada cosa es a la vez, nada y todo, requiere de la totalidad coleccionada y reunida pacientemente para ser asimismo definido por ella en su individualidad, en su hacceidad. Lo ente sale del olvido anónimo mediante su ser reconocido en el todo circundante, es decir, en tanto ocupa un lugar en la memoria de las cosas. Sin embargo el sentido de su propio ser no le pertenece sino que es lo propio de quien ha reunido lo ante la mano en torno suyo y lo ha determinado en su lugar y posición en el ordenamiento de una circunspección que ya sabe con anterioridad hacia dónde dirigirse.

En el esto particular no se esconde su pura presencia sino la reunión del espacio organizado de acuerdo a las referencias y las remisiones mutuas, en las que la mano aparece como el órgano de unidad final. La colección como tal, empero, solo se nos aparece en el momento de la falta, del obstáculo, de su propia constitución incompleta, cuando el reflejo nos permite ver en el vacío de la carencia la totalidad en el momento justo en que ésta se rompe, en que se nos muestra en ausencia y en el que, sobre todo, nos interpela a nosotros como aquellos llamados a completarla para alcanzar su perfección. El mundo circundante de la colección, si bien indefinido en sus límites precisos, es decir, en cuanto al número de entidades que le pertenece, se presenta siempre como acotado, como un acogedor estar rodeado de lo que familiarmente conocemos y que se nos presenta como lo «casero» en el rostro nunca cambiante y soberanamente reposado de lo ente en su mirada vuelta a nosotros y que al hacerlo, nos permite reconocernos a nosotros mismos. Ese universo cerrado de las constelaciones concéntricas, de los lugares bien ordenados en el testimonio de lo que nuestra mano alcanza, se mueve de la totalidad a la particularidad, sin que en ello haya rupturas de sentido, si bien, como se ha dicho, su paso haya de establecerse a través de señales de carencia, de obstaculización o de defecto que habrá siempre que remediar.

La colección es de lo que está a la mano, es decir, de lo que cae bajo esa mano que se moldea y adapta y que en cierto modo es ya todos los entes, pues, en efecto, a todos los acoge y acaricia, a todos les permite expresarse en su función y los acarrea a la cercanía de la totalidad ante la que ella se mueve. La mano agita, desde un fondo común, la singularidad presente, puente de unión entre la extrañeza y la familiaridad, entre lo ente y lo óntico-ontológico del Dasein ${ }^{1}$. La colección de lo ente es la esfera protectora frente a la indeterminación de lo «en-sí», de lo ajeno

1 La concepción de la mano como aquello que no es puro órgano pero tampoco puro ente acompaña a Heidegger durante su obra. Ver por ejemplo la siguiente afirmación (entre otras): "La mano indica, tal vez porque el hombre es un signo». GA 8, 19. Las citas de Heidegger se harán en lo posible tomando en consideración la Gesamtausgabe (GA); y se citará con la sigla GA seguido del tomo y del número de página. La traducción de las citas, mientras no se indique lo contrario, es del autor. 
e inquietante, que no podemos tomar o alcanzar, que no podemos traducir en la forma de nuestro puño que se cierra alrededor de una forma que no vemos en nuestra ocupación pero que siempre podemos sentir. Por ello la necesidad del Dasein de acercar lo lejano, su necesidad de una cercanía pero que aquí no es o no puede ser la del ser sino la de lo meramente ente. ¿Y no está allí, podemos preguntar, el origen de una tecnología que nos alarga el brazo para que la mano pueda cerrarse sobre lo extraño y ajeno y empujarlo poco a poco a la esfera resguardada de nuestra colección? Pero Heidegger no cree eso. La cercanía tecnológica, la radio que nos hace escuchar un concierto en Londres $^{2}$ o la máquina de escribir que acelera nuestra escritura no pertenecen ya a la esfera de lo a la mano sino al rompimiento de la cercanía, a la anulación de la distancia ${ }^{3}$ (que no es ya la Ent-fernung como des-alejamiento ${ }^{4}$ ) sino la pura disponibilidad de lo ente que la tecnología anula y nivela. Es como si Heidegger nos dijera: la cercanía excesiva de la tecnología moderna que hace de lo ente lo puramente disponible para el sujeto cartesiano, no sabe ya nada de lo a la mano, de los espacios, regiones, contradas o lugares vagamente definidos y diferenciados en sus cualidades junto a los cuales nos movemos y existimos, y que son reemplazados por la cuadrícula, la ergonomía, la eficiencia distributiva y fluida de los puestos de trabajo o de las ciudades-máquinas de circulación.

El espacio de vibraciones rítmicas de la esfera inmediata del Dasein solo se abre y se abrió en la época moderna, en el paso a la «imagen del mundo», a partir de las extensiones que permitían hacer de lo turbador y extraño algo ya no ciertamente al alcance de nuestra mano, sino ya solo de nuestros ojos, bien con el telescopio que rompía el silencio de los espacios mudos y abismales, bien el del microscopio que nos adentraba desde el plano físico a la región de las mónadas leibnizianas. Nos rodeamos de panoramas compuestos por siluetas (Abschattungen) carentes de una unidad reconocible y expresable en lo ente "como» ente ("seind als seind») es decir, en el misterio de cuerpos celestes y mundos ínfimos sin referencia a lo visible de nuestro entorno, a la región de lo familiar. Con ello entramos a la dimensión de la objetividad como pura presencia de la imagen puesto que esta no tiene referencia en nuestro mundo circundante y nos acostumbramos a aceptar lo extraño como constituyente fundamental de nuestra cotidianidad. El cambio del régimen visual iniciado por Galileo contiene en sí la imposibilidad de una intencionalidad plena, en tanto conformada por semi-objetos no dados nunca en "carne y hueso" sino bajo la mediación tecnológica del aparato, un ver de segundo orden que acompaña por otro lado la matematización y la idealización de la ciencia ${ }^{5}$.

2 El ejemplo de la radio es particularmente importante para Heidegger, quien lo utiliza desde sus tempranas lecciones hasta sus tardíos enfrentamientos con la esencia de la técnica moderna. Cf. Prolegomena zur Geschichte des Zeitbegriffes, GA 20, 312; Sein und Zeit, GA 2, 141; Holzwege, GA 5, 5; Aufsätze und Vorträge GA 7, 167; Bremer und Freiburger Vorträge, GA 79,38 s. etc.

3 Sobre la máquina de escribir y la ruptura de la palabra y el ser, cf. entre otros lugares, GA 54, 119.

4 Sobre el Ent-fernung y la espacialidad del Dasein, cf. GA 2, 140.

5 Desde el lado de la fenomenología husserliana sería de gran interés retomar lo que ahí está en juego desde una fenomenología de la presentificación intuitiva, tal como ha sido desarrollada sobre todo en el texto Nr. 1 de la Husserliana XXIII titulado «Phantasie und Bildbewusstsein». 
LA COLECCIÓN Y EL HUMANISMO

Las primeras colecciones del siglo XIV estaban determinadas por todo aquello que los antiguos habían alabado y había sido señalado como digno de posesión por Plinio el Viejo en su Historia Natural, pues un humanista digno de ese nombre debía ser ante todo un anticuario y saber encontrar en las piezas que lo rodeaban, la marca de la autenticidad y de la pertenencia al pasado ilustre ${ }^{6}$. Su puesto en la colección debía asegurarse de dos maneras, en cuanto era una clase de objeto ya desde antiguo apreciada y en cuanto podía trazarse una genealogía desde su forma presente hasta su creación antigua. La documentación y el archivo son tan importantes como la pieza misma en la constitución de la colección. En ello también deben incluirse los esfuerzos filológicos de un Lorenzo Valla cuando establece, por ejemplo, que los escritos de Dionisio Areopagita no pueden ser anteriores al siglo VI y así la autoridad de la tradición se ve complementada por el análisis que se encarga de determinar y repartir autenticidades y falsedades.

Poco a poco, en el transcurso del siglo XV la colección se abre para incluir ciertas curiosidades derivadas de las colecciones sacras de reliquias y otras manifestaciones monstruosas acumuladas por las iglesias medievales ${ }^{7}$, las cuales habían interpretado esas monstruosidades como signos divinos, siguiendo la etimología de la palabra recogida por un texto famoso de San Agustín, para indicarnos la presencia de un Dios que puede alterar a voluntad la eternidad de las especies ${ }^{8}$. A ello se juntarán los elementos exóticos que los exploradores portugueses y otros comienzan a traer de sus viajes en el transcurso del siglo. Así, la referencia exclusiva de la colección humanista a la Antigüedad se amplía, sin embargo, sigue siendo esta la principal fuente de elementos coleccionables por lo menos hasta el coleccionismo manierista de Aldrobandi y otros de fines del siglo XVI que coincide con una nueva idea cosmológica, con la ruptura de las esferas de cristal y la ilimitada fantasía de filósofos y científicos. En la figura medial de Galileo vemos la transición entre un mundo cerrado del Renacimiento y un universo infinito del barroco (para parafrasear a Koyré) desde un punto de vista inesperado: en la degradación, según él, del arte de la colección.

En efecto, será el propio Galileo se quejará de la pérdida de dignidad de la colección humanista bajo el manierismo ${ }^{9}$, en tanto pasa de tener las mejores piezas

6 Vgl. Momigliano, A., «Ancient History and the Antiquarian», p. 290. [Cfr. referencias completas en la Bibliografía].

7 Estas colecciones tenían funciones simbólicas. Cf. Lugli, A., Naturalia et Mirabilia. Les cabinets de curiosités en Europe, p. 39. Cf. Findlen, P., «Possessing the Past: The Material World of the Italian Renaissance», p. 86, y Danston, L., PARK, K., Wunder und die Ordnung der Natur 1150-1750, p. 87.

8 «Como no fué imposible para Dios crear las naturalezas que quiso, no lo es tampoco cambiarlas a su gusto. De aquí nacen toda esa serie de milagros que se llaman monstruos, ostentos, portentos y prodigios. Si quisiera referir y recordarlos todos, apuesto que esta obra no tendría fin. Se dice que la palabra monstruo deriva de monstrando, y se llaman así porque muestran en cierta manera el futuro. Ostentos deriva de ostendendo, y portentos, de portendendo, o sea, praeostendendo, y prodigios, de porro dicere, porque predicen el porvenir». Agustín: La ciudad de Dios, XXI, 8, p. 1565.

9 Cf. Panofsky, E., «Galileo as a Critic of the Arts: Aesthetic Attitude and Scientific Thought», pp. 3-15. 
de la Antigüedad, colocadas en anchos y bellos espacios ${ }^{10}$, (Galileo piensa aquí en la Galería de los Uffizzi recién abierta) a un conjunto cualquiera de objetos que un hombrecillo curioso va recolectando sin criterio en su camino, como insectos atrapados en ámbar, un escarabajo egipcio u otras curiosidades orientales a través de las cuales la apertura del ancho mundo se ve reflejada para censura de Galileo ${ }^{11}$. Aquí como en el caso de la nueva astronomía, el orden cósmico y perfecto da paso a la variación, la curiosidad y la extrañeza. Es claro que esa contradicción patente entre los gustos, por decirlo así, estéticos de Galileo y su trabajo científico, solo es tal si se ve el dominio del arte como alejado de la verdad de un mundo que emerge, - todavía incompleto-, despuntando sobre las ruinas del Renacimiento. La contradicción se explica, en el caso de Galileo, por ser él una figura de transición, un humanista en cuerpo de astrónomo y que no puede comprender que él mismo con su obra científica y sus resultados: la visualización de la Luna, los satélites de Júpiter, las fases de Venus y sus postulados del movimiento infinito y de la inercia, ha contribuido a desmoronar. Lo que desea conservar por un lado, lo pierde por el otro, lo que para nosotros es transparente en cuanto vemos la relación entre la espacialidad implícita en los trabajos de Galileo y las colecciones por venir, con su expansión en los museos, la celebración de la variación y la diversidad y no ya de la regularidad y la perfección. El Galileo artista, que busca conservar el ideal regular y coordinado del espacio humanista está en contradicción con la visibilidad del universo que ya no conoce límites ni regularidades sino la pura variabilidad infinita, bien expresada en las ideas cosmológicas de un Giordano Bruno.

El mundo moderno pierde su referencia romana y griega, denuncia Galileo; el lugar compuesto de objetos familiares de las colecciones de su juventud, se ve oscurecido por la presencia de culturas extrañas debidas a los descubrimientos de nuevas regiones y rutas de comercio, a la nueva comprensión del tiempo indefinido que se abre para acoger nuevas tradiciones: la magia egipcia, el hermetismo de Hermes Trismegisto, la nivelación de los espacios. El objeto experimenta mil variaciones, el espacio se abre en torno suyo, de Galileo, y eso lo llena de angustia, lo que podría ser una contradicción para quien propuso matematizar por primera vez un espacio infinito. Porque el espacio galileano será infinito, tal vez, pero no desordenado, será una colección de unidades repetida indefinidamente y en ello se opone entre líneas al caos cósmico de un Giordano Bruno, cuya realidad única es su expresión, y para quien el universo infinito celebra la plasticidad inagotable de la materia, la posibilidad de la que la realidad no es sino una forma momentánea y destinada a perecer. La infinitud de su espacio está al servicio de las formas pasajeras que en manifestaciones continuas y eternas recorren el espectro total

10 «Pero por el contrario cuando entro en el Furioso veo abrirse un guardarropa, una tribuna, una galería real ornada con cientos de estatuas antiguas de los más célebres escultores, con infinitas habitaciones enteras, y las mejores, con pintores ilustres, con un número grande de vasos, de cristales, de ágatas, de lapislázuli y de otras joyas y finalmente llenas de cosas raras, preciosas, maravillosas y de total excelencia». GaLILEI, G., Considerazioni alla Gerusalemme liberata, p. 130-131.

11 «... un cangrejo petrificado, un camaleón seco, una mosca, una araña en gelatina en un pedazo de ámbar, algunos de aquellos escarabajos de tierra que se dice se encuentran en los sepulcros antiguos de Egipto». GaliLeI, G., Considerazioni alla Gerusalemme liberata, p. 130 f. 
de lo ente. La colección será entonces consagrada a la variabilidad pura y en esa variación el siglo XVII encontrará la fuente de la sabiduría, en la fe combinatoria, en el despliegue de lo ente en sus miles y miles de formas y detalles, en el ideal de un teatro de la naturaleza y el arte (Leibniz). Acumular es conocer, ordenar es ya desvelar secretos, combinar es enriquecer el universo, podría ser el lema que estaría detrás de los impulsos leibnizianos por convencer a Pedro el Grande de Rusia de abrir su colección ${ }^{12}$, lo que efectivamente sucederá después de la muerte de Leibniz cuando en 1730 se abra al público el Museo de L'Hermitage en San Petersburgo. Pero entonces la colección habrá perdido su centro, no será ya el humanista que conserva en torno suyo aquello en lo que él es, lo que ama y cuida, sino la celebración del objeto en cuanto tal, en sus miles de formas y manifestaciones, pues nada queda ya al amparo de la curiosidad.

\section{LA COLECCIÓN Y EL HUMANISTA}

El tener a la mano lo que del mundo merece ser rescatado, al amparo del naufragio del tiempo, del desorden y del ruido vano era ya el ideal del primer humanista, de Petrarca y su galería de hombres ilustres, un afán de origen estoico, en el que la serenidad del contemplar desde la orilla los varios oficios y preocupaciones de los hombres, era una forma de contrastar esos afanes con el orden cósmico eterno e inmutable cuya contemplación sería el fin último de la meditación filosófica. Con Petrarca y el arte de la colección por él iniciado, ese orden inmutable e inhumano, se humaniza, se hace representar por aquello que merece ser traído al refugio interior, a la intimidad de la celda del monje o al del studiolo en cada caso privado y propio. Allí, bajo el modelo de los monasterios cartujos, donde la soledad y la autosuficiencia buscan reemplazar el comercio con los hombres, el estudio humanista, el studiolo ${ }^{13}$, desea mantener fuera el ruido de los hombres y reservar el interior para la quietud de un pasado fijo e inamovible, punto fijo del único ideal humano posible. No siendo este el lugar para una comparación detallada, es necesario insistir en la semejanza entre el estoicismo de Séneca, representado por su libro de brevitate vitae, y el de Petrarca, de vita solitaria, aunque claramente lo que en el primero representa la contemplación del cosmos como ideal de vida, será transformado en el segundo y en toda la tradición del Renacimiento por el recuerdo del pasado, por el amor a una historia que es necesario repetir pero nunca superar. El macrocosmos es reemplazado por el microcosmos único y personal, el minúsculo cosmos aristotélico a punto de romperse en la infinitud del silencio del espacio geométrico, será conservado en, —o quizás sería mejor decir, traducido a la forma cuidada y amorosa del estudio humanista, donde cada objeto representa un trozo de vida y sabiduría, donde la colección escribe una historia vital y donde

12 Leibniz, G. W., «Concept einer Denkschrift von Leibniz (für den Czaaren Peter), Dezember 1708», p. 97.

13 Sobre la aparición de este espacio privado, sin antecedentes en las residencias anteriores y cuyo único antecedente bien puede decirse es la celda del monje, ver: LieBENWEIN, W., Studiolo. Die Entstehung eines Raumtyps und seine Entwicklung. 
la separación entre sujeto y objeto no tiene sentido, pues hay una continuidad entre la colección y su poseedor.

Pocas veces podemos trazar y comprender la aparición de una nueva forma espacial y su necesidad como en el caso del studiolo durante el siglo XIV. Ese pequeño espacio aislado del resto de la residencia y al que solo penetraba su dueño, era la morada del espíritu del humanista, en diálogo con los testimonios y los textos del pasado. Allí habitaba el espíritu en el recogimiento y el silencio, sin la penetración no deseada del mundo exterior. Allí encuentra el espíritu su verdadero camino, sin extravíos ni distracciones, según el dicho de Leonardo da Vinci: «Las habitaciones pequeñas conducen al espíritu por la vía correcta, las grandes lo desvían» ${ }^{14}$.

Desde este punto de vista, el desarrollo del método de la perspectiva a comienzos del siglo XV tiene el sentido de interiorizar lo exterior, de recoger en una imagen el mundo exterior para convertirlo en objeto que puede ser integrado a la colección del studiolo. Es el arte que no está ya exclusivamente destinado a la exhibición pública, sino que, como el texto leído mentalmente y no recitado, puede ser contemplado calladamente en la intimidad exclusiva del contemplador. En ello se comprende la nueva manera de captar el espacio, de encerrarlo con el poder del método en la trama cuadriculada y vertical del plano. El mundo que merece ser visto debe serlo como si lo fuera a través de una ventana que no tanto nos da a ver un exterior indomable como nos lo presenta domesticado y encerrado para el uso del observador presente en su estudio ${ }^{15}$. En efecto, la primera representación de un interior en la pintura occidental es la de Petrarca en su estudio ${ }^{16}$, obra de Francesco della Setta y que lo muestra ante sus libros colocados en atriles y gabinetes, bustos y otros elementos indicativos de un ideal humanista que está siendo inaugurado en ese preciso momento, en el que el espacio se convierte en la máquina del tiempo que le permite saltar sobre el presente inerte y acercarse a la gloria del pasado.

De hecho el grabado representa a Petrarca mientras escribe su libro De viribus ilustris una serie de biografías en la que él vendrá para la posteridad a encajar naturalmente. De este modo el grabado mismo anticipa su propia pertenencia a una futura colección de hombres ilustres que ampliará el arco del tiempo para incluir el presente representado. Hay allí entonces frente a Petrarca lo ente en su estar a la mano, su autonomía y la impresión de un tiempo que le pertenece a él fuera de la fatiga del tiempo público con su bullicio, con su solicitud y exigencia. Así en ese arte incipiente de la perspectiva se nos retrata lo que del mundo situado en el allá indiferente de lo común merece ser traído al aquí del coleccionista.

14 Cf. Liebenwein, W., Studiolo, p. 128. La cita original es la siguiente: «le stanze overo abitationi piccole ravian lo ingegno et le grandi lo sviano».

15 Cf. la famosa frase de Alberti en el tratado De Pictura con el que inicia la teoría de la perspectiva en el renacimiento: "Antes que nada, en la superficie que voy a pintar, trazo un rectángulo tan amplio como quiera que es para mi como una ventana abierta a través de la cual la escena será contemplada». Alberti, L. B., Das Standbild, Die Malkunst, Grundlagen der Malerei, p. 19.

16 Cf. Liebenwein, W., Studiolo, p. 54. Esta imagen fue dibujada entre 1367 y 1388 por Francesco de la Setta y se encuentra en el Codex Darmstadt 101, página 1v, Hessische Landes- und Hochschulbibliothek Darmstadt. La imagen representa al humanista durante la composición de su libro De viris illustribus que le fue encargado a Petrarca por Francesco Carrara como texto que debía acompañar al ciclo de frescos de la Sala viriorum illustrium. 
A través del método de la perspectiva el autor mismo puede levantar el velo de lo exterior y permitir su acceso al interior. No es cualquier espacio el así representado, sino el espacio metódico y bien delineado, en el que la simetría del punto de fuga se corresponde con la mira que apunta a un blanco desde el ojo humano. Es el espacio domesticado en el que lo exterior aún no reducido a sus elementos claros y distintos, como la modelo femenina en un famoso grabado de Durero, es obligado a entrar ordenadamente y con la regularidad prescrita por el método a la superficie del pintor. Aquí nos viene a la cabeza la mítica cabaña heideggeriana como refugio pero a su vez como implante en medio del clima, de la tormenta de nieve dónde el filósofo en el refugio de su entorno inmediato encuentra el momento propicio para la filosofía. El modelo de contacto entre hombre y naturaleza es desde Petrarca el jardín. Es esa naturaleza bien ordenada la que se considera aquí como correlato intencional del individuo aislado. El poeta se separa del común de los hombres por un triple alejamiento: el del lugar, el del tiempo, es decir de la noche, cuando aún en el foro citadino reina el vacío y el silencio y el del espíritu que en la fuerza de un profundo ensimismamiento, puede estar solo tanto como quiera y sin saber lo que pasa alrededor aún en medio de la muchedumbre. El humanista se forma a sí mismo en el aislamiento de su espacio, donde las lecturas, los objetos y recuerdos se entretejen para conformarlo a él, para darle forma a su ser sin que en ese espíritu coleccionador aparezca una voluntad de dominar ese mundo objetual.

Un destacado historiador, Ernst Kantorowicz ${ }^{17}$, ha seguido ese ideal de la separación del espíritu de su entorno a los averroístas que al postular la independencia y la pertenencia del intelecto agente a una potencia separada han sentado las bases para la vida paralela del espíritu en medio del ruido mismo del mundo. Sea como sea, la naturaleza entra allí como una dimensión intermedia entre el individuo aislado y la ciudad atareada, signo de la pérdida de medida y sin alguna medida del tiempo. El tiempo es y debe ser el de los ritmos naturales pero de una naturaleza entendida desde la domesticidad del humanista.

Allí es donde habrá de verse la particularidad del reloj como máquina de la modernidad, no como pretende interpretarlo Heidegger, es decir como una simple traducción de la regularidad de los movimientos celestes a un ente a la mano, sino al contrario como reemplazo de una regularidad estelar perdida que ya no puede ser contrapuesta a la imperfección sublunar. Así el reloj se desprende de la dependencia de movimientos circulares y alcanza la perfección del ritmo que los astros no pueden ya garantizar. En ese sentido el reloj es la colección en miniatura de los ritmos cósmicos, pero solo en cuanto convienen a la situación humana y llevados a una perfección que los cielos no poseen y que el mismo reloj puede ahora desvelar. Cuando el cosmos deja de significar lo a la mano de la naturaleza en su ritmo que ata la experiencia humana, ésta solo puede ser constreñida a aparecer como el lejano referente del reloj que del cosmos solo guarda su dependencia de la gravitación. Pero el reloj sirve de puente entre el resguardo de lo familiar y lo indiferente público, hace precaria la frontera entre ambas dimensiones y obliga a pasar sin solución de continuidad de una a la otra ${ }^{18}$.

17 Vgl. Kantorowicz, E. H., «Die Wiederkehr Gelehrter Anachorese», p. 340.

18 Para una exposición detallada de la relación entre reloj y modernidad, ver GARAVITO, J. P. «Modernidad y autómata: el caso del reloj» pp. 119-136. 
Como queda dicho arriba y confirmado por el testimonio del propio Galileo, esa propiedad de la colección va a perderse en la variabilidad pura de lo ente en el siglo XVII. La colección entra en el anonimato del museo (palabra aparecida hacia el año $1600^{19}$ ) y pierde su conexión vital con el coleccionista. El objeto pierde su individualidad, pues no es ya sino el representante de la variabilidad infinita y de la curiosidad investigativa. Es decir, el coleccionista se transforma en el puro acumulador, su figura, tan perfectamente caracterizada por Benjamin, se pierde: «La pasión verdadera y escondida del coleccionista es siempre anárquica y destructiva. Pues esta es su dialéctica: Anudar la fidelidad hacia la cosa, lo único, lo protegido por él, con la obstinada protesta subversiva contra lo típico, lo clasificable» ${ }^{20}$. Pero aquí por supuesto, hemos recorrido el círculo completo, donde el motivo de la colección no es ya sino la memoria perdida de la significación de lo ente a la mano.

\section{DASEIN Y COLECCIÓN}

Más allá de los vacíos propios de su colección de herramientas y demás singularidades familiares en la que no entra el desorden del azar o de lo imprevisto, el Dasein en medio de su ocupación no experimenta la angustiante espera de la nada ni la posibilidad misma de darse en la cara con lo inquietante. El Dasein se halla, como nos dice Heidegger, en estupor ante las cosas en el modo del ocuparse de lo particular. En esa «lívida indeterminación ${ }^{21}$ del ocuparse cotidiano, no halla el Dasein, la plenitud, sino la indiferencia frente al ahí de su ser. Y sin embargo, no está menos abierto a sí mismo desde esa espacialidad propia desde la cual y con la cual el Dasein se proyecta desde su facticidad plena hacia el futuro. Es entonces en esa concreción del hacer donde el Dasein se encuentra en su cotidianidad. Lo ente a la mano no está separado de él, pues se mantiene en una relación de cuidado y orden mutuos, en la que el horizonte de herramientas es el reflejo exacto de los propósitos del Dasein en su actividad, sin representaciones ni entramados artificiales, sin métodos o idealizaciones. La espacialidad de la colección es la que aquí se nos impone como se desprende del hecho de que al Dasein le corresponde como existencial, su capacidad de otorgar espacio (Raumgeben), dar lugar a lo a la mano en términos de su espacialidad ${ }^{22}$. Cuida de lo faltante, de lo llamativo, de lo obstaculizante y en ello se revela la colección como un todo ordenado, de remisiones mutuas y no la simple acumulación de lo que está uno al lado de lo otro al azar y desordenadamente. El mundo circundante del Dasein se abre «por mor de sí mismo" pero el sí mismo no existe sino en el entorno de su propia reunión con lo ente y de su propia espacialidad.

Entonces, sin transición alguna el Dasein cae al mundo de lo público, del Uno y adopta su postura anónima con la que se arropa y se camufla, se mimetiza entre la multitud. La colección ordenada cede el paso a la curiosidad desordenada, la

\footnotetext{
19 Liebenwein, W., Studiolo, p. 163.

20 Benjamin, W., «Lob der Puppe», p. 216 s.

21 Fahle Ungestimmtheit, Cf. GA 2, 179.

22 Cf. GA 2, 148 s.
} 
concupiscentia agustiniana ${ }^{23}$ se convierte en el mecanismo mediante el cual pasamos de la ocupación al conocimiento, es decir, la transformación de lo a la mano a lo ante los ojos, (Vorhandene) ${ }^{24}$. En el mundo de lo público, donde lo ente se señala a partir de un sistema de signos ajeno e impropio, como el de las direccionales del camión recién inventadas en $1927^{25}$, se abre el espacio no ya desde la autonomía de la ocupación circunspecta, sino de la interacción intersubjetiva de la publicidad. Podemos decir entonces, el mundo público, el mundo del nosotros es un bosque de signos, en el que la apropiación manifiesta de lo ente no se da ya a través de la mano ni apunta hacia lo a la mano, del amoldar nuestro órgano a la forma de lo exterior, sino en el transportarse entero a lo allá afuera en nuestra mente y nuestra actividad, que no está ya centrada en un propósito sino dispersa en los objetivos y caminos abiertos por el anónimo Uno. Así, la pretendida seguridad buscada en la reunión de lo que nos enfrenta como lo a la mano y lo familiar termina en el desencanto de una colección que se rompe, incapaz de contenernos en su refugio interior y despertando por el contrario las ansias de buscar la novedad en un exterior caído bajo el dominio del anonimato intersubjetivo.

Nuevamente recordamos al Petrarca autor del libro Del conflicto secreto de mis preocupaciones (De secreto conflicto curarum mearum) cuando habla de la accidia como el pecado de su alma y como la herida mayor de su espíritu. Ésta puede ponerse en relación con la acedia que Casiano en el siglo IV identificó en los monjes de los primeros monasterios occidentales, cuyos síntomas son, entre otros, la inquietud y el afán por visitar monasterios lejanos, el malestar del lugar, la espera impaciente de la caída del sol para poder recibir la comida, y en la que finalmente se declara el vacío en el ahí de su propia soledad ${ }^{26}$.

En medio de esta acedia todo es inquietante y la vía de la desesperación está siempre abierta. La causa de esa tristeza del alma no es una particular sino ese dolor profundo que se siente como cuando está alguien rodeado por innumerables enemigos y no hay salida ni esperanza, ninguna caridad o consolación y todo se le enfrenta en el modo de lo inamistoso. Lo lejano aparece y solo ello, como lo deseable, mientras que lo que está a la mano, su rutina, su cuarto, el monasterio aparece vacío e insignificante, odioso, del latín inodiare, de donde vendrá la francesa ennui. El remedio petrarquiano es dirigir su mirada a su interior y acostumbrarse a ello, de tal modo que cuando tenga el oído así habituado podrá escuchar el escándalo de la masa del pueblo como si fuera el rumor de una cascada y en esa percepción deleitarse, concluye Petrarca.

El recurso al interior es una de las vías señaladas que será reemplazada por otras, digamos utópicas, en las que no solo lo cercano sino también el conjunto de lo ente

23 Cf. GA 2, 227.

24 La Caída y el imperio de lo Uno tienen en Ser y Tiempo el carácter intemporal que caracteriza un existencial y que la referencia a Augustín enfatiza. Sin embargo, en desarrollos posteriores le dará una caracterización propiamente contemporánea, como un mal de la civilización tecnológica y moderna, como modo en que el olvido del ser se revela y donde el rasgo estructural se pierde. Ver por ejemplo el análisis fenomenológico del aburrimiento en GA 29/30 o el texto de circunstancia "Schöpferische Landschaft: Warum bleiben wir in der Provinz?» en GA 13.

25 ...y que Heidegger menciona en Ser y tiempo, GA 2, 104 s.

26 Cf. Cassien, J., Institutions Cénobitiques. 
es transformado como una nueva plenitud del espacio y el tiempo, desde la cual el humanista pueda ocupar su puesto en medio de lo ente y acomodarlo y acomodarse según sus necesidades y gustos. La utopía en ese sentido puede interpretarse como el intento por volver una colección universal la dimensión de lo público, en la cual el humanista pueda volver a sentirse como en casa y desde allí proyectarse a la totalidad del mundo. Es claro que la aparición del pensamiento utópico desde comienzos del siglo XVI tiene que ver con el descubrimiento de un territorio virgen a ojos de los europeos, donde la sociedad puede comenzar de nuevos, así como la utopía como género griego y del cual se desprende las platónicas República o Las Leyes tenía que ver con la colonización del sur de Italia por las ciudades griegas ${ }^{27}$. Pero en el origen de la utopía podemos encontrar también la angustia del intelectual por verse dejado de lado, por no ser ya el cultivador puro de las musas y del pasado, sino aquel para quien es requerida una participación en la vida activa de un continente europeo en pleno despertar. Ahora el studiolo, símbolo del humanista se transforma en limitación y aislamiento, el refugio y la soledad se muestran en su pobreza ante un mundo por hacer. El aburrimiento amenaza al humanista encerrado en su cuarto, ya la colección no le es suficiente para sentirse pleno. Por ello la utopía se presenta como un ideal del espacio y sobre todo, del tiempo. Allí no existe tiempo libre, el tiempo es medido, regulado, llenado, no existe el aislamiento sino la plena comunidad. No es casual que Tomasso Campanella haya escrito su Città del Sole mientras se encontraba en la cárcel; el espíritu no puede ya contenerse en las estancias pequeñas de las que nos hablaba da Vinci. Ahora necesita el espacio total, la administración y división de las partículas de tiempo y espacio de modo que todos tengan algo que hacer, y donde no haya más ocio ni amenaza de aburrimiento.

Si en el ámbito de la colección de lo a la mano, el Dasein aún no manifiesta su caída, dado que allí se sitúa todavía al amparo del chismorreo y la pura curiosidad, del amor a los espectáculos, mientras es un técnico que busca una finalidad determinada, será en el intento de saltar por encima de lo a la mano, de combatir la acedia, la incapacidad para permanecer ya siempre siendo su absorción circunspectiva y empujándose hacia ese espacio ontológicamente incierto de lo público, en que lo ente no es ni a la mano ni es el simple estar ahí de los objetos, donde el Dasein habrá de caer. Si el olvido es, filosóficamente hablando, del sentido del Ser, en el espacio del anonimato de los otros y de la indiferencia curiosa frente a lo que nos sale al encuentro es el ente mismo el que se olvida.

En la salida a lo público el coleccionista olvida su colección, es decir la preservación de la singularidad en la totalidad, la conservación de lo único en cuanto el espacio cerrado creado alrededor de sus necesidades como un guante que protege de la exterioridad amenazante se vuelve poroso y abierto. La pasión del coleccionista queda deshecha, pues el espacio es ahora nivelado y regular, sin cualidades ni propiedades, sin relación con su proyecto, sino que se objetiviza en el allá de la imagen bajo el modo del se (se piensa, se dice, se critica, etc.)

Entre la colección cerrada y reconfortante en cuanto devuelve un rostro familiar del humanista y ese mundo exterior de lo público se alza un abismo de incertidumbre

27 Ver sobre esto el texto de Gadamer, H.-G., "Platos Denken in Utopien», en Ges. Werke vol. 7 . 
y de descontrol, pues el tiempo y el espacio se descomponen en múltiples dimensiones que el coleccionista desde su studiolo no puede dominar. La memoria se disuelve, ya que la colección es un ars memoriae, desde donde se apoya el recuerdo del mundo en su totalidad. La colección está unida por los hilos que la atan al pasado y al presente, al tiempo y al espacio, que en la salida a lo público se pierde y donde sólo la adopción mimética del lenguaje y de los signos que en él se hallan impiden que se olvide del todo el mundo originario, pero que como ruinas de una realidad anterior se desvanecen, restos de un naufragio en el mar del tiempo. La memoria es reemplazada por la curiosidad, el ente por su palabra, el orden de las cosas por el del discurso.

Así, la utopía es la intención de salvar del olvido al mundo caído en lo público, de llevarlo a una perfección perdida, la versión secularizada de esa apokapadokía tes ktíseos de la carta de San Pablo a los Romanos y que Heidegger citará en una lección posterior a Ser y Tiempo como la añoranza de las criaturas ante la carencia de un mundo ${ }^{28}$, ante el abandono metafísico de una época ya no es presidida por el mayor coleccionista de todos, Dios mismo. La utopía se establece para saltar por encima de aquello que ha sido salvado del océano de la indiferencia pero a costa de olvidar el mundo mismo; es decir para rescatar del vacío y de la nada al individuo que observa los límites de su colección, cuando el mundo exterior sigue avanzando a su propio ritmo y lo deja detrás, cuando la contemplación deseada no es más posible en un mundo que se mueve a partir de su propia actividad. La utopía redefine el espacio y el tiempo de acuerdo al ideal de un nuevo orden que desde el individuo conquiste al mundo público, donde el tiempo esté siempre regulado y el espacio sea una nueva unidad conjunta, donde la melancolía y el aburrimiento hayan sido definitivamente expulsados en una reconciliación del tiempo individual y del tiempo maquinal, artificial. Por ello la utopía tendrá el carácter de aislamiento, donde lo extraño no venga a interrumpir el sueño de lo propio, donde el nosotros y el ello no puedan confundirse, pues sólo así ha de conquistarse esa nueva unidad cerrada centrada ahora en el destino de un pueblo y un estado, donde la novedad ha sido expulsada por innecesaria y contraria al orden deseado. En la ciudad utópica el nosotros se vuelve coleccionista de espacios y tiempos microcósmicos que llevan consigo la posibilidad de duplicación indefinida de su esencia, ante la cual el vacío y el infinito de los espacios siderales dejarán de tener un aspecto monstruoso para pasar a ser formas posibles de la repetición. Sólo allí podrá escapar el humanista/ coleccionista/Dasein tanto del lastre de su propia actividad encerrada en los límites de un Intérieur insuficiente, como de la dictadura del tiempo y el espacio públicos, así como de la opacidad del lenguaje común y conquistar por fin el silencio, la meditación y la integración definitiva al todo. En la repetición auténtica de su temporeidad propia encontrará el Dasein su descanso utópico, su destino histórico.

\section{Conclusión: el Dasein y los humanismos}

Una crítica que se escucha a menudo entre algunos de los filósofos influenciados por Heidegger es la de que este autor simplifica en exceso el problema del humanismo

28 Cf. GA 29/30, 396. 
igualándolo con la metafísica, en cuanto toda metafísica se basa en una determinada esencia humana y particularmente en su forma moderna el humanismo no es sino el cartesianismo del sujeto como hipokéimenon, como sustrato de la verdad de lo ente. Con ello, para Heidegger, en la modernidad se renuncia a preguntarse por la verdad del ser en cuanto tal, pues esta pregunta queda oculta bajo la esencia de lo «humano» ${ }^{29}$. Para estos autores, me refiero aquí sobre todo a Gadamer ${ }^{30}$ y a Grassi ${ }^{31}$, existe en la tradición humanista una contracorriente que se opondría a la lógica de la proyección matemática de la naturaleza y a la concepción del hombre como un sujeto pensante y dueño de la verdad de lo ente a través del método. Existiría un primer humanismo preocupado no por la centralidad del hombre sino del mundo, de la historia y del lenguaje y que es, en esta misma línea de pensamiento, el que hemos intentado rastrear aquí a través del concepto de colección. Ese primer humanismo, —es también la tesis de los autores citados anteriormente-, no está tan alejada de la concepción del Dasein heideggeriano y representa un modo de la propiedad (Eigentlichkeit) que se contrapone a la caída en el uno y que se encuentra en la concentración sobre sí de lo ente, para trascenderlo y apropiarlo, pero no ya bajo el modo del conocimiento sino de su temporeidad e historicidad. El humanismo metafísico cartesiano es la dispersión de ese primer momento del humanista coleccionador en tanto este intenta salvar lo ente de la ruina y del olvido, para pasar a reflejarlo del modo indiferente del conocimiento matemático, donde lo ente queda reducido a no ser sino un punto de masa y una distancia geométrica y se olvida su entidad y su pertenencia al mundo. En el ruido de las máquinas, nuestro llamado al pastoreo del lenguaje deja de ser escuchado y en nuestro alejamiento de aquello más cercano, del Ser, del Hogar, del fuego eterno, se pierde la posibilidad de salvación.

\section{BibLiografíA}

Obras de Heidegger citadas o referidas en el texto según la Gesamtausgabe, todas ellas editadas por Vittorio Klostermann:

GA 2 Sein und Zeit, Friedrich-Wilhelm von Herrmann (Ed.), Frankfurt/Main 1977.

GA 5 Holzwege, Friedrich-Wilhelm von Herrmann (Ed.), Frankfurt/Main 1977.

GA 7 Vorträge und Aufsätze, Friedrich-Wilhelm von Herrmann (Ed.), Frankfurt/Main 2000.

GA 8 Was heisst Denken?, Paola Ludovica Coriando (Ed.), Frankfurt/Main, 2002.

GA 9 Wegmarken, Friedrich-Wilhelm von Herrmann (Ed.), Frankfurt/Main 1976.

GA 13 Aus der Erfahrung des Denkens, Hermann Heidegger (Ed.), Frankfurt/Main 1983.

GA 20 Prolegomena zur Geschichte des Zeitbegriffs, Sommersemester 1925, Petra Jaeger (Ed.), Frankfurt/Main 1979.

29 Así, en su Brief über den «Humanismus» nos dice Heidegger: «El humanismo no solo no se pregunta por la determinación de la humanidad de lo humano desde la relación del Ser con la esencia humana sino que impide esta pregunta, pues él, dado su origen en la metafísica, no la conoce ni la entiende». GA 9, 321; cf. también GA 7, 93.

30 Ver la primera sección de su libro Wahrheit und Methode:Grundzüge einer philosophischen Hermeneutik, 2010, titulada: Bedeutung der humanistischen Tradition für die Geisteswissenschaft (Significación de la tradición humanista para las ciencias del espíritu).

31 GRASsi, E., Heidegger y el problema del humanismo. 
GA 29/30 Die Grundbegriffe der Metaphysik: Welt, Endlichkeit, Einsamkeit, Wintersemester 1929/30, Friedrich-Wilhelm von Herrmann (Ed.), Frankfurt/Main 1983.

GA 53 Hölderlins Hymne «Der Ister», Sommersemester 1942, Walter Biemel (Ed.), Frankfurt/ Main 1984.

GA 54 Parmenides, Freiburger Vorlesung Wintersemester 1942/43, Manfred S. Frings (Ed.), Frankfurt/Main 1982.

GA 79 Bremer und Freiburger Vorträge, Petra Jaeger (Ed.), Frankfurt/Main 1994.

Otras obras citadas:

Alberti, L. B. (2000). Das Standbild, Die Malkunst, Grundlagen der Malerei, editor y traductor Oskar Bätschmann, Wiss. Darmstadt: Buchges.

Agustín, La Ciudad de Dios, trad. Santos Santamarta del Río y Miguel Fuertes Lanero, Biblioteca de Autores Cristianos, Madrid, 2001.

Benjamin, W. (1980). «Lob der Puppe», Gesammelte Schriften, Vol. III, Rolf Tiedemann (Ed.), Suhrkamp, Frankfurt/Main, p. 213-218.

Cassien, J. (1965). Institutions Cénobitiques. Texte latin revu, introduction, traduction et notes par Jean-Claude Guy, S. J. Paris: Cerf.

Danston, L.; Katharine, P. (2002). Wunder und die Ordnung der Natur 1150-1750. Berlin: Eichborn.

Findlen, P. (1998). «Possessing the Past: The Material World of the Italian Renaissance», en: The American Historical Review, Vol. 103, Nr. 1, p. 83-114.

Gadamer, H.-G. (2010). Wahrheit und Methode:Grundzüge einer philosophischen Hermeneutik. Tübingen: Mohr Siebeck.

Gadamer, H.-G. (1991). Gesammelte Werke, Vol. 7 Griechische Philosophie III. Tübingen: Mohr Siebeck.

Galilei, G. (1856). Considerazioni alla Gerusalemme liberata, in: Le Opere di Galileo Galileo, Bd. XV. Firenze: Società Editrice Fiorentina.

Garavito, J. P. (2012). «Modernidad y autómata: el caso del reloj», en: Poéticas de la biología de lo posible, Pontificia Universidad Javeriana, pp. 119-136.

Grassi, E. (2006). Heidegger y el problema del humanismo, trad. y notas Ubaldo Pérez Paoli. Barcelona: Anthropos.

Guerrier, W. (2001). Leibniz in seinen Beziehungen zu Russland und Peter dem Grossen. (Replica of 1873, edition by Kaiserliche Akademie der Wissenschaften, St. Petersburg und Leipzig), Elibron Classics.

Kantorowicz, E. H. (1965). «Die Wiederkehr Gelehrter Anachorese», en Selected Studies by Ernst H. Kantorowicz. Locust Valley, NY: J. J. Augustin Publisher.

Liebenwein, W. (1977). Studiolo, Die Entstehung eines Raumtyps und seine Entwicklung. Berlin: Gebr. Mann.

Lugli, A. (1998). Naturalia et Mirabilia. Les cabinets de curiosités en Europe, introd. de Roland Recht. Paris: Société Nouvelle Adam Biro.

Momigliano, A. (1950). "Ancient History and the Antiquarian», Journal of the Warburg and Courtauld Institutes, Vol. 13, Nr. 3/4, p. 285-315.

Panofsky, E. (1956). «Galileo as a Critic of the Arts: Aesthetic Attitude and Scientific Thought», Isis, Vol. 47, Nr.1, S. 3-15.

Pontificia Universidad Javeriana

Juan Pablo Garavito Zuluaga

Facultad de Filosofía

Bogotá

[Artículo aprobado para publication en dismember de 2016] 